\title{
A BUSCA PELAS PARCERIAS NA CONCRETIZAÇÃO DOS OBJETIVOS DE DESENVOLVIMENTO SUSTENTÁVEL - ODS
}

\section{ARTIGO ORIGINAL}

CARNEIRO, Dioclécio Salomão ${ }^{1}$

CARNEIRO, Dioclécio Salomão. A busca pelas parcerias na concretização dos Objetivos de Desenvolvimento Sustentável - ODS. Revista Científica Multidisciplinar Núcleo do Conhecimento. Ano 05, Ed. 04, Vol. 05, pp. 76-88. Abril de 2020. ISSN: 2448-0959, Link de acesso: https://www.nucleodoconhecimento.com.br/lei/objetivos-de-desenvolvimento

\section{RESUMO}

A pesquisa busca retratar uma vertente dos Objetivos de Desenvolvimento Sustentável, em seu estudo voltado para a instrumentalização do desenvolvimento da democracia, baseado nas parcerias de fortalecimento da sociedade civil. O problema da pesquisa está justamente na hipótese de que as garantias e manutenção dos direitos fundamentais devem se utilizar do fomento como atividade do Estado ao lado das Parcerias. Objetiva, portanto, o franco interesse nas Parcerias como meio propulsor da democracia participativa, além da necessidade de mecanismos jurídicos cada vez mais objetivos e específicos para atender essas organizações. Para isso foram utilizadas a pesquisa bibliográfica disponível além do recurso eletrônico disponível. Entretanto não se pretende esgotar o assunto abordado, contudo é possível concluir como resultado desta, de que as parcerias do Estado com o ente privado poderão proporcionar garantias constitucionais para a efetivação de direitos fundamentais sociais.

\footnotetext{
${ }^{1}$ Mestrando em Direito Constitucional. Direitos Fundamentais e Democracia. Bacharel em Direito e Ciências Contábeis.
} 
Palavras-chave: Direito Constitucional, democracia, parcerias, sustentabilidade.

\section{INTRODUÇÃO}

A proposta enaltecida pelos Objetivos de Desenvolvimento Sustentável - ODS buscam em sua essência tratar de assuntos relacionados ao bem-estar das pessoas, através dos instrumentos que fortalecem a paz universal da mesma forma que evidencia a liberdade. Questões essas somadas a erradicação da pobreza, no que tange ao cume dessa anomalia social com o olhar para o futuro do qual todos possam usufruir das riquezas naturais com equilíbrio e sem prejudicar a cada geração futura.

O desafio para o desenvolvimento global se pauta na atuação colaborativa e participativa de todos os entes sociais, tanto no planejamento como na execução desse plano engajado nos objetivos estratégicos. Nas palavras da Organização das Nações Unidas vê-se que a proposta é decidida em propiciar a liberdade dos seres humanos de toda fonte de tiranos, da pobreza, penúria, além da busca pela cura, protegendo assim o planeta. (NAÇÕES UNIDAS, 2019). Com esse alinhamento os ODS tomam como premissa a atuação arrojada e transformadora em caráter de urgência para um mundo melhor, de forma coletiva e com o sentimento de que todos os sujeitos podem e devem caminhar juntos rumo ao desenvolvimento participado.

\section{DESENVOLVIMENTO SUSTENTÁVEL E SEUS OBJETIVOS. AGENDA DE GARANTIA DOS DIREITOS FUNDAMENTAIS NOS ODS}

Um breve histórico para situar o leitor de que as questões relacionadas a sustentabilidade estão pontuadas com os estudos propiciados pela ONU, cuja organização possui o caráter de direcionamento e estabilidade das tensões políticas inerentes às diferentes culturas e pensamentos dos países que forma o globo. O que se entende pela sustentabilidade do desenvolvimento, orquestrados pelos mais diferentes estudos da Organização das Nações Unidas retrata em essência as alterações provocadas no clima, sendo de forma evidente o resultado e consequência para a humanidade junto a crise da sociedade e do ambiente vivenciados na metade do século XX até os dias atuais. (BARBOSA, 2008). Para tanto, os fatores que levam 
o avanço tecnológico e prosperidade social, são temas de abordagem e preocupação da ONU.

O registro que data a conceituação da sustentabilidade no desenvolvimento, historicamente foi consumado na Agenda 21, protocolo esse criado na Conferência "Rio 92", e posteriormente aplicado para outras participações mundiais para com o desenvolvimento e direitos humanos. Entretanto cabe destacar que esse conceito está perenemente em construção como segundo a maioria dos pesquisadores descrevem o tema, como exemplo Carla Canepa (2007), José Eli da Veiga (2005) e Henri Ascelard (1999). (BARBOSA, 2008). A pertinência do assunto é tão direta e ao mesmo tempo complexo do qual se faz necessário a abordagem sistêmica referente aos resultados que se quer alcançar.

Importante destacar as rejeições em alguma medida dos objetivos sustentáveis propostos, haja visto a provocação que se faz junto a definição-padrão de desenvolvimento sustentável, cujo será a de não decadência do bem-estar/sujeito motivado pela evidente busca ao modelo de equidade entre nações $e$ gerações. (BARONI, 1992). Portanto é nesse foco que se busca a estabilidade do sistema de apoio mútuo entre as nações do globo.

Ao interpretar e escrever sobre o assunto sustentabilidade, não se deve colocar em patamar intermediário e sim como princípio potencial que denota ações e planejamento futuro. Contudo, trata-se de um direito fundamental, possibilitando descortinar a sustentabilidade em um duplo papel. É fonte, como caráter norteador, interpretativo e ponderador, mas, também, enquadra-se como norma fundamental. (GOMES E HENRIQUE, 2018). Os reflexos pautados nessa análise hermenêutica possibilitam o arranjo jurídico como além do instrumento prático e filosófico em torno do dever ser sustentável, possível e que contenha em essência o bem-estar social sem deixar de fora gerações presentes e futuras.

Os documentos e relatórios gerados pelas Nações Unidas referem-se ao processo de que os objetivos para desenvolver o milênio de certa forma foram bem-sucedidos, pois propiciaram o crescimento da economia, melhores práticas políticas e o dever 
compromissado do globo em sentido a esse desenvolver, para tanto percebe-se um encolhimento da extrema pobreza, apesar de se ter pessoas no mundo a dentro sobrevivendo com menos de $\$ 1,25$ dia. (GALLO, 2014). E é justamente nesse ponto de equilíbrio de tensões políticas, sociais e econômicas que se destacam certamente o envolvimento e capacidade de articulação para com a Organização e países dos quais formam a grande maioria da população mundial.

Importante destacar as diversas conceituações donde o "pano" de fundo integra de maneira a construir e concretizar o mais amplo e necessário ato de reorganização do espaço, local de ocorrência das relações sociais, de modo a redefinir relações essas no campo político e econômico, cujos juntos geram resultados de mudança de perfis de governança para os espaços de democracia e propriamente a função de existir do Estado. (CAMPANHOLA, 2000). No tocante a influência gerada e patrocinada pelos ODS se tem a clara noção e entendimento da tamanha capacidade argumentativa, expositiva e influenciadora de opiniões políticas dentro de um Estado soberano, e sendo esse justamente o objetivo principal da formação de opinião como elemento capaz de melhorar as condições sociais.

A garantia da paz, do bem-estar e da estabilidade no contexto do pós-guerra, ainda numa parte histórica para o contexto, dependia assim de um concerto entre Estado, mercado e instituições democráticas, inclusive internacionalmente, o que se respaldou nos acordos de Bretton Woods e na criação de instituições internacionais. (NETO E FISCHER, 2018). A busca pelo equilíbrio voltado para as ações Estatais se complementa de força em absoluto ao alinhamento dos ODS, haja visto possuírem enorme congruência para objetivos além dos individuais, mas sim coletivos em que governo algum poderá abrir mão em não propiciar sua implantação.

A participação do Estado teria como uma de suas fortes atribuições a promoção do pleno emprego, o fortalecimento da economia e bem-estar de seus cidadãos, enquanto seu poder era distribuído ao lado dos processos de mercado. (NETO E FISCHER, 2018). Por mais que se garanta total liberdade econômica, há que se ressaltar a importância da mediação de um mercado próspero e capaz de absorver 
com qualidade o potencial humano na geração de riquezas sustentáveis para o presente e futuras gerações.

As parcerias estão previstas como um dos Objetivos do Desenvolvimento Sustentável da ONU por tratar-se de um dos instrumentos mais relevantes na concretude dos objetivos gerais como um todo. O Objetivo de número 17 diz: tornar forte os mecanismos que concretizam e revitalizam os parceiros a nível de globo com a sustentabilidade para com o desenvolvimento. As metas específicas incluem as áreas de finanças, tecnologia, capacitação, comércio, bem como questões sistêmicas e cooperação em ciência, tecnologia e inovação. (NAÇÕES UNIDAS, 2019). A Organização ciente da ampla necessidade de apoiar-se nas bases fundamentais com a economia por exemplo, segue elevando o estado desse objetivo como padrão a ser seguido nas diferentes áreas do desenvolvimento técnico das diferentes áreas do conhecimento humano.

\section{DEMOCRACIA PARTICIPATIVA. FOMENTO COMO ATIVIDADE DO ESTADO. TERCEIRO SETOR}

Falar em democracia, como unidade de participação ampla da sociedade civil organizada, na conduta de decisões a serem geridas, do qual o Estado figura como detentor do recurso público arrecadado, mas também por força de alento ao ato de organizar e prestar o recurso de atendimento as mais diferentes carências da humanidade, fazendo com que os gestores públicos e seus respectivos conselhos de políticas públicas garantam experiências e expertises no trato a democracia participativa do Brasil atual. Os conselhos, cujos estão distribuídos na grande maioria dos municípios brasileiros, fazem essa articulação desde a gama federal, estando presente nos vários setores que estruturam a sociedade, seja assuntos tratados no âmbito da saúde, educação, moradia, meio ambiente, transporte, cultura, dentre outros, mostrando assim a concretude dessa magnífica conquista brasileira cujo fortalecimento das entidades democráticas está presente entre nós. O tema principal será o de apostar cada vez mais no diálogo perene entre governo e sociedade num canal público, plural, do coletivo para o indivíduo, numa via de mão dupla perfazendo 
assim o investimento mais justo, solidário e eficiente do recurso público. (TATAGIBA, 2005). E nesse patamar de que se espera avançar quanto mais fomentado por organizações como a ONU no sentido de nortear as ações de cada governo, sem retirar-Ihes sua soberania, mas guiando para o caminho mais acertado, haja visto não haver sociedades ou comunidades más e sim maus líderes.

Apenas como forma de esclarecer ao leitor de que o sistema democrático representativo através de partidos, tem-se de forma intrínseca, quando séria, respeitosa e honesta, os instrumentos instituídos para servir a vontade popular quando necessária sua manifestação. Ressalte-se ainda o instrumento de excelência quando de sua viabilização é o plebiscito, mas também outros previstos na Constituição Brasileira, seja o referendum, a iniciativa popular, além de outros. (BEÇAK, 2008). Esses instrumentos somados ao delineamento de objetivos claros de desenvolvimento não impostos, mas convencidos, argumentados e influenciadores de opinião somam como sendo o meio mais eficiente e rápido para as nações, principalmente aquelas que se encontram em pleno desenvolvimento. Terem nos objetivos do desenvolvimento sustentável mais um mecanismo colocado a disposição para o melhor a ser extraído da ideia de inserir todos numa condição de igualdade de oportunidades.

Conforme destaca (EBERHARDT, 2015), os instrumentos da democracia tradicional (partidos, urnas e militantes) deixaram lugar para a intervenção, vigilância e controle de uma cidadania informada, atenta e cada vez mais impaciente. Este novo ator (a cidadania impaciente e indignada) ocupa não só as maiores praças de todas as cidades do mundo, monopoliza também todos os segundos do rádio e televisão seja de canais públicos ou privados. Portanto, a diferença dessa nova cidadania é que não só se opõem, mas também propõem.

Para isso a importância dos ODS como sendo além do olhar para o desenvolvimento, mas também como objeto de aferição de dados estatísticos a serem colocados à disposição das populações, haja visto tratar-se do termômetro social em caráter de desenvolvimento social, econômico, científico e cultural por exemplo. Percebe-se que dentro de um conjunto de diferentes níveis ou estágios de desenvolvimento a 
consolidação da participação de conselhos se mostra em trajetória crescente na política de avanço desses sistemas universais de participação popular, fortalecendo assim o conteúdo gradual de mobilização e organizacional dos atores sociais, e por consequência, a maneira vislumbrada de atuação dos sujeitos de governo atrelados. Pontual, 2008. Volta-se a registrar que de nada adianta a mera formalidade de criação de conselhos representativos por exemplo, como instrumentos de participação democrática, se não houver objetivos claros de padrão até internacional, não desmerecendo as atuações caseiras, mas as experiências de outros países aceleram em alguma medida os percalços na busca da sustentabilidade desviando-se de situações negativas anteriormente sofridas por outras nações.

Um dos principais fatores de aceleração no processo de transformação do Estado é o atual contexto das grandes mudanças ocorridas há alguns anos em todo o globo, destaque aos países que primam pela aceleração de seus processos de democratização e desenvolvimento, no que tange as políticas de globalização, o avanço tecnológico da informação e a urgente necessidade da sociedade civil organizada em acelerar seu estado de bem-estar social. As principais funções deste novo Estado são a regulação, a representatividade política, a justiça e a solidariedade. Pimenta, (1998). Desta forma se vê com passos largos o Estado se desprendendo de algumas ações e contraindo outras, o que culmina para uma mudança de comportamento cujo movimento do ente público se dá de produtor direto de bens e serviços para um instituto universal regulador e indutor do desenvolvimento, ou mesmo até em um sistema misto de atuações na economia para pleitear através da ação ágil, inovadora e democrática do objetivo claro de eficiência equânime fronte as mais diversas necessidades sociais.

A reforma proposta por Bresser, retratava a necessidade de restringir o Estado de forma a limitar algumas atribuições, principalmente no que diz respeito a produção de bens e serviços e por outro viés, com menor amplitude, como agente regulador, todavia implicaria na ampliação de suas funções de financiamento de organizações públicas não-estatais. Já esse recurso, demanda tributos para permear a possibilidade de crédito ao inserir a sociedade como principal ator de desenvolvimento 
econômico e todos os demais por consequência. Desta forma para construção de ações ligadas as externalidades ou direitos básicos humanos se mostrem envolvidos, carecem sim, de subsídios e instrumentos abarcados pelo Estado, para então propiciar a competitividade externa frente as indústrias locais por exemplo. (BRESSER-PEREIRA, 1997). Esse relato já observado em longa data, demonstra que é necessário a figura do Estado como um dos principais articuladores de estabilidade social, através do crescimento com qualidade seja no emprego, cultura, saúde, educação e demais pilares da realidade social.

Para (FISCHER, 1998), inova ao dizer que as ações de governo abrem espaço para entidades não governamentais, apresentando e aplicando propostas descentralizadoras, dos quais repassam a municípios atividades que até então eram exercidas por órgãos federais e estaduais ou subordinados a esses, recomendando assim a participação da comunidade nas decisões além do incurso das entidades sem fins lucrativos em sua operacionalização. Haja visto adequar-se a realidade de características brasileiras na sua complexidade, tamanho e diversidade, além da capacidade de democratizar a prestação do serviço público conforme suas necessidades locais. Desta forma garante o fortalecimento das organizações do Terceiro Setor como agente legítimo de competência local.

Como sabe-se países em desenvolvimento sofrem com a berlinda da geração de renda, podendo-se reiterar o centro de necessidades sociais brasileiras no que tange ao mercado de trabalho, cujo ciclicamente sofre perturbações advindas de razões de conjuntura estrutural desse país. Percebe-se também a crescente e diversificada, além da multiplicação das carências de atendimento à sociedade, englobando outras que não apenas de mercado de trabalho, e sim nas áreas de saúde, assistência social, educação, transporte, lazer, cuidados físicos e mentais. (RODRIGUES, 1998). Muitos desses fatores negativos estão presentes não necessariamente por questões atreladas na economia, mas por questões relacionadas a políticas de governo mal planejadas. Portanto nesse cenário poder-se-á aplicar através das parcerias, como já descrito na agenda da ODS um instrumento capaz de amortecer 
essas influências e ainda assim dar prestação de serviço público com qualidade além da geração de renda continuada e adequada.

\section{PERCEPÇÃO SOCIAL DOS EFEITOS ORIUNDOS DOS} ODS. MANUTENÇÃO DAS GARANTIAS FUNDAMENTAIS DA SOCIEDADE. PARCERIAS PARA OS ODS COMO ELEMENTO GARANTIDOR DAS CONQUISTAS FUNDAMENTAIS SOCIAIS

Assim como todo instrumento de melhoria continuada se faz necessário o acompanhamento da real eficiência na ponta da necessidade social, para isso os controles e diagnósticos atribuídos ao Estado além da própria sociedade civil organizada são capazes de demonstrar e apontar a necessidade de ajustes de conduta no decorrer da prestação do serviço. Cabe ressaltar que para tornar-se factível e viável, as agendas requerem formas e mecanismos de governança estratégicas, utilizando-se da intersetorialidade, capilaridade e interescalaridade para parametrizar as ações territoriais, insumos de quantificação e avaliação suficientes para produção de vistas a efetividade em correlação a sustentabilidade do desenvolvimento. (GALLO, 2014). Para além do finalístico principal, o de prevalecer o Estado como indutor de políticas públicas, das quais são em sua maioria advindas de agendas políticas, essa permeabilidade para que a sociedade civil organizada possa atuar em todo o processo democrático de desenvolvimento sustentável da sociedade.

O setor produtivo na esfera privada segue a cada dia com um papel mais claro, plenamente conhecido pelos atores sociais, incluindo os governos, sociedade civil organizada e o próprio cidadão que constrói sua interpretação das práticas aplicadas na economia, pela condição de inovação e capacidade tecnológica. A transformação dos recursos da economia, aliados a capacidade em transformá-los através de ações de ordem coordenada pelos setores afins, aflora uma verdadeira permissão pela transformação do molde existente do desenvolvimento, acrescenta Alba na entrevista ao Centro de Informação das Nações Unidas para o Brasil (UNIC Rio). (NAÇÕES UNIDAS, 2019). Nesse aspecto verifica-se a maturidade da sociedade, concentrando o eixo de desenvolvimento em todos os atores sociais, e não apenas buscar como 
fonte primária única e exclusiva da participação do Estado no elemento propulsor do desenvolvimento social para todos, haja visto tornar essa participação privada como sendo mais um instrumento de incentivo a concorrência de serviços básicos, intermediários ou até de alta complexidade, frente as necessidades dos cidadãos a custos módicos e acessível para as camadas mais pobres ou desassistidas.

Contudo a existência da sociedade civil anterior ao Estado não implica na desnecessidade do Estado. Não se quer delegar tudo e a qualquer modo entregar às parcerias as atividades tidas como de atribuição prestacional exclusiva do Estado, mas ao contrário trazer ainda mais a participação da sociedade para de fato tornar democrático o quanto possível o recurso público, para toda a população e não ao contrário para beneficiar pequenas parcelas ao bel prazer de políticas de governo.

O destaque que (ABBOUD, 2011) traz, está em definir que a sociedade civil possui como garantia de efetivação de seus direitos a presença do Estado juntamente com a legislação produzida por seus representantes na política. Desta forma o Estado se apresenta como instrumento de aperfeiçoamento da tutela de direitos, bem como na sua delimitação, além da seguridade frente as liberdades individuais no intento de prevenção ao conflito de radicalidades. Assegura-se, portanto, um Estado não criador de leis e obrigações, mas sim de melhoria, aperfeiçoamento e resguardo desses mesmo direitos sociais fundamentais.

Surgindo dessa proposta, na perspectiva de democratizar o serviço prestacional em parcerias do Estado com a iniciativa privada, vê-se um meio de fortalecimento das ligações entre os cidadãos e seu Estado. Fomentar o cooperativismo entre o privado e o ente público, limitado e balizado em condições e requisitos da economia circular, de forma a conduzir formas e modelos que visam a sustentabilidade no desenvolvimento, com o foco em regiões ou áreas menos favorecidas. Portanto, esclarece as (NAÇÕES UNIDAS, 2019), de que as condutas da razoabilidade no quesito de sustentabilidade interferem diretamente na condição de desigualdade, infraestrutura e resiliência. Como exemplo, a distribuição do poder político afeta as decisões do governo sobre investimentos em infraestrutura. Por sua vez a resiliência da infraestrutura afeta a resiliência das pessoas. Por outro lado, a infraestrutura 
prejudicada precariza o fornecimento de serviços básicos, a mudança na produtividade e o acesso aos bens, serviços e oportunidades de emprego, tudo isso gera por consequência a desigualdade, seja de oportunidades, seja a discriminação que afetam normas, interações sociais e por si a resiliência. (ONU, 2019).

\section{CONSIDERAÇÕES FINAIS}

A distribuição do poder político no gerenciamento do Estado é capaz de determinar as áreas de investimento e desenvolvimento social, portanto a agenda política é o instrumento adequado e democrático para se elevar demandas sociais pertinentes de inserção do recurso público. Por conta dessas escolhas em sua grande maioria relacionadas à infraestrutura de atendimento básico da população, causa de certa maneira desigualdades macro e microrregionais dentro do mesmo espaço geográfico continental como o caso do Brasil. Setores ou regiões melhor aparelhadas conseguem entregar maior cobertura com qualidade reduzindo assim a deficiência no atendimento das demandas sociais, caso contrário soma-se a desigualdade entre populações. A infraestrutura mal desenvolvida restringe o acesso aos bens de consumo, serviços, oportunidade de trabalho e renda, por conseguinte gera-se a desigualdade num ciclo vicioso.

Toda essa desigualdade desenfreada, provoca inicialmente uma espécie de resiliência do qual a estagnação do desenvolvimento humano prende-se de forma a prejudicar com sequelas de demorada reversão no ambiente democrático. Por essas razões torna-se prudente e necessário o preenchimento equânime do serviço público com a ajuda de entidades do terceiro setor, cuja forma de parcerias na soma de esforços capazes de mudar a realidade, seja ela local, regional ou nacional, afim de acelerar a concretude dos objetivos de desenvolvimento sustentável. Formando assim uma espécie de âncora capaz de afixar renda, produtividade, eficiência, redução de custo e melhor distribuição de ações Estatais voltadas para o bem-estar social. 


\section{REFERÊNCIAS}

ABBOUD, Georges. O mito da supremacia do interesse público sobre o privado: a dimensão constitucional dos direitos fundamentais e os requisitos necessários para se autorizar restrição a direitos fundamentais. Revista dos Tribunais, v. 907, p. 61, 2011.

BARBOSA, Gisele Silva. O desafio do desenvolvimento sustentável. Revista Visões, v. 4 , n. 1, p. 1-11, 2008.

BARONI, Margaret. Ambigüidades e deficiências do conceito de desenvolvimento sustentável. Revista de administração de empresas, v. 32, n. 2, p. 14-24, 1992.

BEÇAK, Rubens. Instrumentos de democracia participativa. Manaus: CONPEDI, p. 5932, 2008.

BRESSER-PEREIRA, Luiz Carlos. Estratégia e estrutura para um novo Estado. 1997.

CAMPANHOLA, Clayton; DA SILVA, José Graziano. Desenvolvimento local e a democratização dos espaços rurais. Cadernos de Ciência \& Tecnologia, v. 17, n. 1, p. 11-40, 2000.

EBERHARDT, Maria Laura. Rev. direitos fundam. democ., v. 18, n. 18, p. 182-227, jul./dez. 2015.

FISCHER, Rosa Maria; FALCONER, Andrés Pablo. Desafios da parceria governo e terceiro setor. Revista de administração, v. 33, n. 1, p. 12-19, 1998.

GALLO, Edmundo; SETTI, Andréia Faraoni Freitas. Território, intersetorialidade e escalas: requisitos para a efetividade dos Objetivos de Desenvolvimento Sustentável. Ciência \& Saúde Coletiva, v. 19, p. 4383-4396, 2014.

GOMES, Magno Federici; HENRIQUE, Lisiane Aguiar. Revista de Direitos Fundamentais \& Democracia, Curitiba, v. 23, n. 1, p. 87-106 jan./abr., de 2018. 
NAÇÕES UNIDAS. Nações Unidas Brasil, 2019. Desenvolvimento Sustentável. Disponível em: <https://nacoesunidas.org/setor-privado-e-essencialpara-mundo-cumprir-acordo-climatico-diz-enviado-especial/> Acesso em: 26/07/2019.

NAÇÕES UNIDAS. Nações Unidas Brasil, 2019. Desenvolvimento Sustentável. Disponível em: <https://nacoesunidas.org/tema/ods17/> Acesso em: 26/07/2019.

NAÇÕES UNIDAS. Nações Unidas Brasil, 2019. Agenda 2030. Disponível em: <https://nacoesunidas.org/pos2015/agenda2030/> Acesso em: 26/07/2019.

NAÇÕES UNIDAS. Nações Unidas Brasil, 2019. Documentos Temáticos. em: $<$ http://www.br.undp.org/content/brazil/pt/home/library/ods/documentos-tematicos-ods-1--2--3--5--9--14.html> Acesso em: 26/07/2019.

NETO, Alfredo Copetti; FISCHER, Ricardo Santi. Rev. direitos fundam. democ., v. 18, n. 18, p. 254-274, jul./dez. 2015.

OLIVEIRA, G. J. de. Enciclopédia Jurídica da PUCSP, tomo II (recurso eletrônico). São Paulo: Pontifícia Universidade Católica de São Paulo, 2017.

PIMENTA, Carlos César. A reforma gerencial do Estado brasileiro no contexto das grandes tendências mundiais. Revista de Administração pública, v. 32, n. 5, p. 173199, 1998.

PONTUAL, Pedro. Desafios à construção da democracia participativa no Brasil: a prática dos conselhos de gestão das políticas públicas. Coleção Cadernos da CIDADE, v. 12, n. 14, 2008

RODRIGUES, Maria Cecília Prates. Demandas sociais versus crise de financiamento: o papel do terceiro setor no Brasil. Revista de Administração Pública, v. 32, n. 5, p. 25-67, 1998. 
TATAGIBA, Luciana. Conselhos gestores de políticas públicas e democracia participativa: aprofundando o debate. Revista de Sociologia e Política, n. 25, p. 209213, 2005.

Enviado: Setembro, 2019.

Aprovado: Abril, 2020. 